\title{
Prevalence of behavioral and psychological symptoms of dementia and its association with the degree of cognitive impairment in patients presenting to the National Institute of Mental Health, Sri Lanka
}

D M A Dahanayake, L L A Isuru, N N K Aththanayake, S N Hewage, C K Ranasinghe

\section{Background}

Behavioral and psychological symptoms of dementia (BPSD) are a major contributor to high levels of carer burden and poor quality of life in patients with dementia. Optimal management is yet to be determined. It is imperative to understand the occurrence of BPSD with the severity of cognitive impairment, since this would allow caregivers and healthcare workers to predict likely behavioral and psychological issues.

Aims

To describe the patterns of BPSD among patients admitted to the National Institute of Mental Health (NIMH), Sri Lanka and its association with the degree of cognitive impairment.

\section{Methods}

A cross-sectional descriptive study was carried out among patients diagnosed with dementia admitted to NIMH over a two-year period from 2013. An interviewer administered questionnaire, the mini mental state examination and the Neuropsychiatric Inventory (NPI) were used.

\section{Results}

Of the total 122 patients, $51.6 \%$ were females. The mean age was 71.2 years. According to the MMSE scores, the severity of dementia was mild, moderate and severe in $32.8 \%, 42.6 \%$ and $24.6 \%$ participants respectively. All were on pharmacological treatment in the form of antipsychotics and/or acetylcholinesterase inhibitors. A majority (96.72\%) had BPSD. Frequent symptoms included delusions (42.6\%), irritability (41\%), appetite changes (34.4\%) and depression (32\%). Aberrant motor behavior, sleep and night-time behavior disorders were significantly associated with increased severity of dementia, while irritability, disinhibition, agitation, hallucinations and delusions were significantly higher in moderate dementia. Anxiety and depression were mostly seen in mild dementia.

\section{Conclusion}

A majority of participants had BPSD, despite being on pharmacological treatment. There was a statistically significant prevalence in groups of symptoms, according to the degree of cognitive impairment can be seen.

Key words: dementia, behavioral and psychological symptoms of dementia, factor analysis, Neuropsychiatric inventory.

SL J Psychiatry 2016; 7(1): 4-8

\section{Introduction}

Behavioural and psychological symptoms of dementia (BPSD) are non-cognitive symptoms of dementia, and are defined as 'symptoms of disturbed perception, thought content, mood or behaviour that frequently occur in patients with dementia' $(1,2)$. BPSD, as a group, is not a uniform entity; these symptoms vary over time according to the course of the disease, biological correlates and psychosocial determinants (3). Behavioral and psychological problems were recognised as an integral part of dementia from the description by Esquirol in 1838. He noted that 'demence senile' may be accompanied by emotional disturbances (4). Alois Alzheimer, in his earlier case description of Alzheimer's disease, identified behavioral symptoms as prominent manifestations of the disorder (5). BPSD are now considered as to be as clinically significant as the cognitive symptoms of dementia.

It was estimated that there were 24.3 million people with dementia across the globe in 2001, and it is projected that this will increase to 42.3 million in 2020 (6). In Sri Lanka, the percentage of the population aged over 60 years is predicted to rise to $21 \%$ in 2025 (7). South Asia's fastest aging population is in Sri Lanka, according to a World Bank report 2006, Sri Lanka aging survey. This steep rise has major implications for the provision of resources for the elderly, and dementia care in particular. Behavioural and psychological symptoms have an effect on almost all people with dementia at some point during the progression of the disorder (8). Recent evidence 
recognises that BPSD are accountable for an outsized share of the suffering of patients and caregivers. It increases direct and indirect cost of care, even after adjusting for severity of cognitive impairment and other co-morbidities (9). BPSD are amongst the top causes for poor quality of life, caregiver burden, increased cost of care and fostering of institutionalization. Thus, optimum management of these symptoms will improve the quality of life and wellbeing of both patients and carers (10).

BPSD may differ according to the severity of cognitive impairment, and identifying symptoms which are commonly seen in mild, moderate or severe dementia would be useful in educating caregivers and preparing them for possible future occurrence of symptoms (11).

It is imperative to identify behavioral sub syndromes in dementia rather than studying separate behavioral and psychological symptoms, for the reason that these syndromes may have a common neurobiological basis or may respond to the same treatments (12). It would be clinically useful to identify symptom categories within the cluster of BPSD symptoms. Previous researchers have described four behavioral sub-syndromes, namely hyperactivity, psychosis, affective symptoms, and apathy, based on factor analysis using the Neuropsychiatric Inventory (12). Personally customized approaches which include consideration of all these aspects, are needed in order to formulate more effective pharmacological and non-pharmacological treatments for persons suffering from dementia.

\section{Methods}

A cross-sectional descriptive study was conducted at a psycho-geriatric unit of NIMH, Sri Lanka. This is the only dedicated unit for psycho-geriatric care in the government sector. All the patients in the sample had been on medication for these conditions for a minimum of three weeks, when the assessment was carried out.

The study was conducted over a two-year period from first October 2013, and all patients who met inclusion criteria during this period were included in the study. Patients with a past history of psychiatric disorder, Parkinson's disease dementia, Lewy body dementia and delirium were excluded from the study. The mini mental state examination (MMSE), which is validated for Sri Lanka, was administered to assess for cognitive functions $(13,14)$. Based on the MMSE score, participants were categorised as suffering from mild (MMSE total score $>=21)$, moderate $(11-20)$ or severe $(=<10)$ dementia. The Neuropsychiatric Inventory (NPI) was also administered, which assesses twelve symptom domains as reported by the caregiver (15). It also assesses frequency, severity and caregiver distress in each domain (16). The MMSE scores and the twelve BPSD categories were assessed operationally and administered by trained medical officers. The NPI score was calculated by multiplying the frequency and severity of each individual symptom. Socio-demographic factors were assessed using an interviewer administered questionnaire.
Data are presented as percentages for discrete variables, and as mean with standard deviation for continuous variables. The difference between groups was assessed using a chi-square test for categorical data. Factor analysis was performed on the NPI scores with the aim of identifying the domains of symptoms. Ethical clearance was obtained from the NIMH Ethics Review Committee.

\section{Results}

Data were collected from 122 patients, all of who were on antipsychotics and/or acetylcholine esterase inhibitors. Of the participants, $51.6 \%$ were females. The mean age of this sample was 71.28 years $(\mathrm{SD}=7.82)$, the mean duration of cognitive impairment was 2.9 years $(\mathrm{SD}=1.37$ ). The percentage of mild, moderate and severe dementia was $32.8 \%, 42.6 \%$ and $24.6 \%$ respectively. The majority $(62.9 \%)$ had one or more medical co-morbidities. Hypertension was the commonest medical co-morbidity (36.9\%) followed by diabetes mellitus (16.7\%).

The commonest BPSD was delusions (42.6\%) followed by irritability (41\%), appetite changes (34.4\%), depression (32\%), agitation (31\%) and hallucinations (22.1\%) (Figure 1).

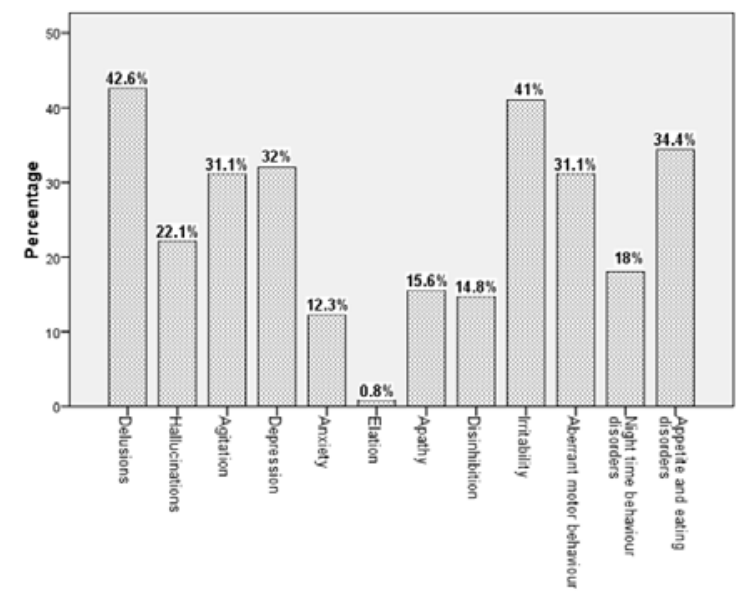

\footnotetext{
Figure 1. Proportions of varying behavioural and psychological symptoms of dementia among participants in this study.
}

There was an identifiable clustering of symptoms, according to the severity of cognitive impairment. Delusions, hallucinations, agitation, disinhibition and irritability were significantly more prevalent in moderate dementia $(\mathrm{p}<0.05)$. Depression and anxiety symptoms were overrepresented in mild dementia, whereas, aberrant motor behavior and sleep and night-time behavior were highly prevalent in severe cognitive impairment $(\mathrm{p}<0.05)$. Apathy and appetite changes were seen across the categories of cognitive impairment (Table 1). 


\begin{tabular}{|c|c|c|c|c|c|}
\hline \multirow{3}{*}{ NPI symptom } & & \multicolumn{3}{|c|}{ Dementia category based on MMSE score } & \multirow{3}{*}{$\begin{array}{c}\text { Chi Square / } \\
\text { Fisher's Exact } \\
\text { test } \\
\text { p }\end{array}$} \\
\hline & & Mild & Moderate & Severe & \\
\hline & & Frequency (\%) & Frequency (\%) & Frequency (\%) & \\
\hline \multirow[t]{2}{*}{ Delusions } & Yes & $16(30.8 \%)$ & $32(61.5 \%)$ & $4 \quad(7.7 \%)$ & \multirow[b]{2}{*}{$<0.001$} \\
\hline & No & $24(34.3 \%)$ & $20(28.6 \%)$ & $26(37.1 \%)$ & \\
\hline \multirow[t]{2}{*}{ Hallucinations } & Yes & $3(11.1 \%)$ & $23(85.2 \%)$ & $1 \quad(3.7 \%)$ & \multirow{2}{*}{$<0.001$} \\
\hline & No & 37 (38.9\%) & $29(30.5 \%)$ & $29(30.5 \%)$ & \\
\hline \multirow[t]{2}{*}{ Agitation } & Yes & $8(21.1 \%)$ & $27(71.1 \%)$ & $3 \quad(7.9 \%)$ & \multirow{2}{*}{$<0.001$} \\
\hline & No & $32(38.1 \%)$ & $25(29.8 \%)$ & $27(32.1 \%)$ & \\
\hline \multirow[t]{2}{*}{ Depression } & Yes & $21(53.8 \%)$ & $16(41.0 \%)$ & $2 \quad(5.1 \%)$ & \multirow{2}{*}{$<0.001$} \\
\hline & No & 19 (22.9\%) & 36 (43.4\%) & $28 \quad(33.7 \%)$ & \\
\hline \multirow[t]{2}{*}{ Anxiety } & Yes & $10 \quad(66.7 \%)$ & $5(33.3 \%)$ & $0 \quad(0.0 \%)$ & \multirow{2}{*}{$0.006^{*}$} \\
\hline & No & $30 \quad(28.0 \%)$ & 47 (43.9\%) & $30 \quad(28.0 \%)$ & \\
\hline \multirow[t]{2}{*}{ Elation } & Yes & $0 \quad(0.0 \%)$ & $1(100.0 \%)$ & $0 \quad(0.0 \%)$ & \multirow{2}{*}{$1.000^{*}$} \\
\hline & No & 40 (33.1\%) & 51 (42.1\%) & 30 (24.8\%) & \\
\hline \multirow[t]{2}{*}{ Apathy } & Yes & 7 (36.8\%) & $10 \quad(52.6 \%)$ & 2 (10.5\%) & \multirow{2}{*}{0.293} \\
\hline & No & 33 (32.0\%) & $42 \quad(40.8 \%)$ & $28(27.2 \%)$ & \\
\hline \multirow[t]{2}{*}{ Disinhibition } & Yes & $1 \quad(5.6 \%)$ & 11 (61.1\%) & 6 (33.3\%) & \multirow{2}{*}{0.028} \\
\hline & No & 39 (37.5\%) & 41 (39.4\%) & $24 \quad(23.1 \%)$ & \\
\hline \multirow[t]{2}{*}{ Irritability } & Yes & 15 (30.0\%) & 28 (56.0\%) & 7 (14.0\%) & \multirow{2}{*}{0.022} \\
\hline & No & 25 (34.7\%) & 24 (33.3\%) & 23 (31.9\%) & \\
\hline \multirow{2}{*}{$\begin{array}{l}\text { Aberrant motor } \\
\text { behaviour }\end{array}$} & Yes & 4 (10.5\%) & 11 (28.9\%) & $23(60.5 \%)$ & \multirow{2}{*}{$<0.001$} \\
\hline & No & 36 (42.9\%) & 41 (48.8\%) & $7 \quad(8.3 \%)$ & \\
\hline \multirow{2}{*}{$\begin{array}{l}\text { Night time } \\
\text { behaviour disorders }\end{array}$} & Yes & $2 \quad(9.1 \%)$ & 9 (40.9\%) & 11 (50.0\%) & \multirow{2}{*}{0.003} \\
\hline & No & 38 (38.0\%) & $43 \quad(43.0 \%)$ & 19 (19.0\%) & \\
\hline \multirow{2}{*}{$\begin{array}{l}\text { Appetite and } \\
\text { eating disorders }\end{array}$} & Yes & 13 (31.0\%) & 19 (45.2\%) & 10 (23.8\%) & \multirow{2}{*}{0.912} \\
\hline & No & 27 (33.8\%) & 33 (41.3\%) & $20(25.0 \%)$ & \\
\hline
\end{tabular}

*Probability calculated from Fisher's exact test after collapsing 'Moderate' and 'Severe' columns into one, forming a 2 by 2 table, due to the presence of cells with zero counts.

During factor analysis of the symptom scores, all extraction methods available in SPSS were tried, and the most convincing solution was obtained from the principal component based method. In order to obtain the most appropriate result, all the rotation methods were carried out on the solution from the principal component based method. The final solution that gave the most suitable explanation from the extracted factors was seen with Varimax rotation (Table 2). A five factor solution was decided based on the criterion of having eigenvalues greater than 1 . The largest contributors from the initial variables to the obtained factors were decided based on the factor loadings. The solution explained $67.2 \%$ of the original variance. More than $60 \%$ of the variance of each of the original variables were included in the selected factor solution, except for the original variable Elation.
The resulting 5 factors were: Factor 1 - contributed by delusions and irritability, Factor 2 - contributed by depression and anxiety, Factor 3 - contributed by aberrant motor symptoms, sleep and night time behavior and appetite loss, Factor 4 - contributed by agitation, apathy and disinhibition and factor 5 - contributed by hallucinations.

\section{Discussion}

The prevalence of BPSD between studies has always been inconsistent, owing to differences in setting, instruments used, study design and sample size. However, the Nakayama study, Cache County Study and Cardiovascular Health Study (19) used largely similar research methodology and instrument (NPI), and the prevalence of BPSD was in agreement between these 


\begin{tabular}{|c|c|c|c|c|c|c|}
\hline \multirow{2}{*}{ NPI Symptoms } & \multicolumn{5}{|c|}{ Factor Loadings } & \multirow{2}{*}{ Communality } \\
\hline & Factor 1 & Factor 2 & Factor 3 & Factor 4 & Factor 5 & \\
\hline Delusions & 0.840 & 0.056 & -0.147 & -0.005 & 0.182 & 0.763 \\
\hline Hallucinations & 0.161 & 0.106 & -0.109 & 0.152 & 0.739 & 0.618 \\
\hline Agitation & 0.103 & 0.482 & -0.027 & 0.518 & 0.392 & 0.665 \\
\hline Depression & 0.180 & 0.837 & -0.054 & 0.097 & 0.007 & 0.746 \\
\hline Anxiety & -0.044 & 0.738 & -0.098 & -0.215 & -0.118 & 0.616 \\
\hline Elation & 0.036 & -0.133 & 0.047 & -0.014 & 0.635 & 0.425 \\
\hline Apathy & -0.481 & -0.015 & -0.166 & -0.576 & 0.302 & 0.681 \\
\hline Disinhibition & -0.113 & -0.138 & -0.049 & 0.751 & 0.155 & 0.622 \\
\hline Irritability & 0.900 & 0.100 & -0.070 & -0.016 & 0.091 & 0.833 \\
\hline $\begin{array}{l}\text { Aberrant motor } \\
\text { behaviour }\end{array}$ & -0.151 & -0.304 & 0.687 & 0.161 & -0.030 & 0.614 \\
\hline $\begin{array}{l}\text { Night time behaviour } \\
\text { disorders }\end{array}$ & -0.107 & -0.128 & 0.806 & 0.022 & -0.142 & 0.699 \\
\hline $\begin{array}{l}\text { Appetite and eating } \\
\text { disorders }\end{array}$ & 0.076 & 0.355 & 0.738 & -0.261 & 0.183 & 0.778 \\
\hline
\end{tabular}

Extraction Method: Principal Component Analysis.

Rotation Method: Varimax with Kaiser Normalization.

studies (17-19). The commonest behavioral and psychological symptoms identified in the present study (delusions, irritability, appetite change and depression) are higher than rates reported in previous studies. A possible reason could be that patients with the above mentioned symptoms were more likely to be admitted, and thus more likely to be included in our study, which was institution based rather than community based. In keeping with this, the prevalence of apathy in our study was $15.6 \%$, whereas it was much higher ( $>50 \%)$ in most of the other studies (20).

The factors identified in the current study were: hostile suspiciousness (delusions and irritability), over-activity (aberrant motor symptoms, sleep and night time behavior and appetite loss), frontal lobe symptoms (agitation, apathy and disinhibition), affective symptoms (depression and anxiety) and hallucinations. These are compatible to some extent with previous clinical studies, which have consistently reported similar factors, including psychosis, frontal lobe symptoms, over-activity and affective symptoms $(12,21)$.

\section{Limitations}

A major limitation of the study is the difficulty of generalizing these results to the overall population of those with dementia in the community; since this sample was institution based, where patients with greater frequency and severity of BPSD are more likely to be present. Additionally, since information was collected from caregivers, there is a possibility of biased interpretation of patients' symptoms. Finally, the concurrent use of acetylcholine esterase inhibitors and psychotropic agents may have altered the frequency, severity and total scores of BPSD.

\section{Conclusions}

The findings of this study give rise to several important implications. The high prevalence of BPSD in patients with dementia highlights the importance of screening for behavioral and psychological symptoms. The majority of participants had BPSD, despite being on acetylcholine esterase inhibitors and/or psychotropic medications; this indicates the need for developing alternate strategies for effective management. The fact that some of the symptoms are correlated with the degree of cognitive impairment, and the clustering of BPSD in mild, moderate and severe dementia may indicate that BPSD is a function of cognitive impairment. A factor analytic approach to BPSD revealed five identifiable subsyndromes which may facilitate the identification of aetiology, and of more specific and effective treatment modalities. 


\section{Declaration of interest}

None declared

DMA Dahanayake, LLA Isuru, NNK Aththanayake, CK Ranasinghe, National Institute of Mental Health, Angoda

SN Hewage, Independent Researcher

Corresponding author: LLA Isuru

Email: amila.isuru23@gmail.com

\section{References}

1. Lawlor B. Managing behavioural and psychological symptoms in dementia. Br J Psychiatry 2002; 181: 463-5.

2. Behavioral and Psychological Signs and Symptoms of Dementia: Implications for Research and Treatment. Proceedings of an international consensus conference. Lansdowne, Virginia, April 1996. Int Psychogeriatr 1996; 8 Suppl 3: 215-552.

3. Robert P, Verhey F, Byrne EJ, et al. Grouping for behavioral and psychological symptoms in dementia: clinical and biological aspects. Consensus paper of the European Alzheimer disease consortium. Eur Psychiatry 2005; 20(7): 490-6.

4. Albou P. Esquirol and dementia. Hist des Sci médicales 2012; 46(1): 45-53.

5. Hippius H, Neundörfer G. The discovery of Alzheimer's disease. Dialogues Clin Neurosci 2003; 5(1): 101-8.

6. Ferri CP, Prince M, Brayne C, et al. Global prevalence of dementia: a Delphi consensus study. Lancet 2005; 366(9503): 2112-7.

7. de Silva A. Alzheimer's disease in Sri Lanka. J Ceylon College of Physicians 2003; 36: 14-26.

8. Tariot PN, Mack JL, Patterson MB, et al. The behavior rating scale for dementia of the consortium to establish a registry for alzheimer's disease. The behavioral pathology committee of the consortium to establish a registry for alzheimer's disease. Am J Psychiatry 1995; 152(9): 1349-57.

9. Murman DL, Colenda CC. The economic impact of neuropsychiatric symptoms in Alzheimer's disease: can drugs ease the burden? Pharmacoeconomics 2005; 23(3): 227-42.
10. Green CR, Marin DB, Mohs RC, Schmeidler J, Aryan M, Fine E, et al. The impact of behavioral impairment of functional ability in Alzheimer's disease. Int J Geriatr Psychiatry 1999; 14 (4): 307-16.

11. Aalten P, Verhey FR, Boziki M, et al. Consistency of neuropsychiatric syndromes across dementias: results from the European Alzheimer Disease Consortium. Part II. Dement Geriatr Cogn Disord 2008; 25(1): 1-8.

12. Aalten P, de Vugt ME, Lousberg R, Korten E, Jaspers N, Senden B, et al. Behavioral problems in dementia: a factor analysis of the neuropsychiatric inventory. Dement Geriatr Cogn Disord 2003;15(2): 99-105.

13. Folstein MF, Folstein SE, McHugh PR. 'Mini-mental state'. A practical method for grading the cognitive state of patients for the clinician. J Psychiatr Res 1975; 12: 189-98.

14. de Silva HA, Gunatilake SB. Mini Mental State Examination in Sinhalese: a sensitive test to screen for dementia in Sri Lanka. International Journal of Geriatric Psychiatry. 2002 Feb; 17 (2): 134-9.

15. Cummings JL, Mega M, Gray K, Rosenberg-Thompson S, Carusi DA, Gornbein J. The Neuropsychiatric Inventory: comprehensive assessment of psychopathology in dementia. Neurology. 1994; 44(12): 2308-14.

16. Kaufer DI, Cummings JL, Christine D, et al. Assessing the impact of neuropsychiatric symptoms in Alzheimer's disease: the Neuropsychiatric Inventory Caregiver Distress Scale. J Am Geriatr Soc. 1998; 46 (2): 210-5.

17. Ikeda M, Fukuhara R, Shigenobu K, et al. Dementia associated mental and behavioural disturbances in elderly people in the community: findings from the first Nakayama study. J Neurol Neurosurg Psychiatry. 2004; 75: 146-8.

18. Lyketsos CG, Sheppard JM, Steinberg M, et al. Neuropsychiatric disturbance in Alzheimer's disease clusters into three groups: the Cache County study. Int J Geriatr Psychiatry 2001; 16: 1043-53.

19. Lyketsos CG, Lopez O, Jones B, Fitzpatrick AL, Breitner J, DeKosky S. Prevalence of neuropsychiatric symptoms in dementia and mild cognitive impairment: results from the cardiovascular health study. JAMA 2002; 288: 1475-83.

20. Savva GM1, Zaccai J, Matthews FE, et al. Prevalence, correlates and course of behavioural and psychological symptoms of dementia in the population; Br J Psychiatry 2009; 194(3): 212-9.

21. Aarsland D, Bronnick K, Ehrt U, et al. Neuropsychiatric symptoms in patients with Parkinson's disease and dementia: frequency, profile and associated care giver stress. J Neurol Neurosurg Psychiatry 2007; 78: 36-42. 